\title{
Com a palavra, 0 trabalhador da Atenção Primária à Saúde: potencialidades e desafios nas práticas educacionais
}

Tiago Rocha Pinto(a)

Eliana Goldfarb Cyrino ${ }^{(b)}$

Pinto TR, Cyrino EG. Listening to the primary health care worker: potential and challenges in educational practices. Interface (Botucatu). 2015; 19 Supl 1:765-77.

This study investigated the potential of and obstacles to the consolidation and implementation of teaching and learning activities experienced in the interaction between students and workers in Primary Health Care Services (APS). We conducted qualitative research using semi-structured interviews with professionals from different categories and APS services of a mediumsized municipality of São Paulo, Brazil. Data were analyzed according to a historicalcultural approach and the explanatory method developed by Vygotsky. This study found that APS scenarios have been established on a key educational basis that meets the principles of the Brazilian Health System (SUS). However, adjustments and agreements are necessary between constituent organizations, health units, and managers in charge of this joint effort so that the students, workers, and population can benefit.

Keywords: Health education. Primary health care. Patient care team.
Este estudo buscou analisar as potencialidades e os entraves na consolidação e operacionalização das atividades de ensino e aprendizagem vivenciadas na interação entre estudantes e trabalhadores dos serviços de Atenção Primária à Saúde (APS). Realizou-se pesquisa qualitativa, por meio de entrevistas semiestruturadas com profissionais de diferentes categorias e serviços da APS de um município de médio porte do estado de São Paulo. Os dados foram analisados segundo a abordagem histórico-cultural, de acordo com o método explicativo de Vigotski. Constatou-se que os cenários da APS têm se constituído enquanto campo fundamental de aprendizagem para uma formação que atenda aos preceitos do SUS. Entretanto, faz-se necessária uma série de ajustes e pactos entre os órgãos formadores, unidades de saúde e gestores encarregados desta articulação, para que alunos, professores, trabalhadores e população possam ser beneficiados com essa intervenção.

Palavras-chave: Educação em saúde. Atenção primária à saúde. Equipe de assistência ao paciente.

\footnotetext{
(a) Escola Multicampi de Ciências Médicas do Rio Grande do Norte. Avenida Doutor Carlindo de Sousa Dantas, 540, $2^{\circ}$ andar. Caicó, RN, Brasil. 59300-000. tiagorochapinto@hotmail.com (b) Departamento de Gestão da Educação na Saúde, Secretaria de Gestão do Trabalho e da Educação na Saúde

(SGTES), Ministério da Saúde. Brasília, DF, Brasil. eliana.cyrino@saude.gov.br
} 


\section{Introdução}

Com a constituição do Sistema Único de Saúde (SUS) e dos princípios doutrinários e organizativos que o orientam, foi desencadeada uma série de transformações no modo com que são ofertados os cuidados em saúde. As Instituições de Ensino Superior (IES), por sua vez, também foram levadas a rever a maneira com que vinham formando seus alunos, na tentativa de se adequarem a estas novas exigências.

Neste ideário, nas últimas décadas, o Ministério da Saúde (MS), em parceria com o da Educação (MEC), têm formulado várias propostas destinadas a promoverem mudanças na formação, em consonância com as Diretrizes Curriculares Nacionais dos Cursos da Área de Saúde (DCNs), assim como para o desenvolvimento da Política de Educação Permanente dos trabalhadores, tais como: Programa de Incentivo às Mudanças Curriculares nos Cursos de Medicina (Promed); Aprender-SUS; Ativadores de processos de mudança; VER-SUS; Programa Nacional de Reorientação da Formação Profissional em Saúde (Pró-Saúde) e o Programa de Educação pelo Trabalho para a Saúde (PETSaúde) ${ }^{1-6}$.

Mais recentemente, o Programa de Valorização dos Profissionais da Atenção Básica (PROVAB), o PET-Redes de Atenção e a Lei do Mais Médicos também passaram a integrar estas ações e, de forma distinta, buscam responder à falta de programas e profissionais em áreas remotas ou de maior vulnerabilidade social1-6.

De modo geral, a perspectiva adotada nestes programas se coaduna às bandeiras de luta dos diversos movimentos sociais surgidos nas últimas décadas, ponderando a importância da integração ensino-serviço para uma formação voltada para as necessidades de saúde da população e do sistema de saúde vigente no país ${ }^{6}$.

Com o apoio das políticas indutoras de mudança, as IES vêm buscando reorganizar seus currículos e cenários de formação, o que tem passado diretamente pela articulação com a rede de atenção à saúde 7.8 . Nas novas DCNs do curso de graduação em medicina de 2014, a Atenção Primária à Saúde (APS) é colocada na centralidade deste processo, desde o início da formação, constituindo-se como cenário obrigatório em $30 \%$ da carga horária no internato ${ }^{5}$.

Estudos apontam para as potencialidades da inserção longitudinal de alunos na APS na perspectiva da educação pelo trabalho, que, aliada ao uso de metodologias ativas de ensino-aprendizagem, revelam-se como estratégias fundamentais para o desenvolvimento de uma concepção ampliada do processo saúde-doença, com possibilidades de uma abordagem integral e contextualizada dos pacientes, famílias e comunidade ${ }^{9-11}$.

Em razão das DCNS e de iniciativas políticas do MS e MEC, é importante destacar que as possibilidades de se produzirem maiores ou menores mudanças dependem do modo como se inaugura o processo, com que se constrói a agenda de discussão e as propostas de inovação ${ }^{12}$. As dificuldades reais do sistema e os embates entre ensino e cuidado no exercício de uma nova lógica sanitária em curso, carregam conflitos, instabilidades e incertezas entre políticas e organizações fortemente instituídas.

Deste modo, a relação entre IES e serviços também pode gerar tensionamentos decorrentes: da dicotomia entre o ensino e a produção de cuidados em saúde, da heterogeneidade de necessidades e interesses institucionais na integração do ensino com a rede de serviços ${ }^{12,13}$.

No que diz respeito à articulação entre ensino e assistência nos cenários da APS, alguns autores já apresentaram complicadores que se fazem presentes nesta relação, tais como: a escassez e a pouca interlocução com equipamentos comunitários; infraestrutura inadequada das unidades de saúde; alta rotatividade de profissionais, além da falta de compreensão sobre a necessidade de educação permanente como forma essencial para a reflexão sobre o processo de trabalho e qualificação das práticas assistenciais ${ }^{14-16}$.

Muitos profissionais que atuam na APS consideram que atividades pedagógicas e de preceptoria fazem parte das suas atribuições, e gostariam de desempenhá-las adequadamente. Todavia, 
responsabilizam as IES e gestores pela pouca valorização e estímulo a estas ações, dificultando o desenvolvimento de competência técnica para se trabalhar e problematizar a realidade com os alunos.

Num contexto de crescente demanda e ocupação da APS por alunos de diferentes cursos, disciplinas e momentos da formação, torna-se indiscutível a necessidade de construção de espaços de compartilhamento de saberes e de modos de ver o cotidiano do cuidado entre docentes, estudantes, usuários e profissionais dos serviços.

Ao se ouvir a percepção dos profissionais sobre a interação com alunos, espera-se contribuir com a literatura existente, apresentando alguns reflexos das políticas indutoras de mudança em saúde no cotidiano de trabalho das equipes.

Assim, o presente artigo tem por objetivo analisar as potencialidades e entraves na consolidação e operacionalização das atividades de ensino e aprendizagem vivenciadas na interação entre estudantes de graduação em formação na saúde e trabalhadores dos serviços de APS.

\section{Metodologia}

O presente manuscrito é parte da investigação do projeto: "Integração Universidade, Serviços de Saúde e Comunidade na FMB-UNESP: construindo novas práticas de formação e pesquisa", financiado pela CAPES (Edital nº 024/ 2010). Na perspectiva de estudantes, professores e profissionais de saúde, o projeto contempla diferentes frentes de análise, como: a formação em educação permanente de professores tutores (docentes da universidade e profissionais da saúde e da educação que atuam na APS); o desenvolvimento da clínica e da medicina narrativa no ensino na APS, e a visita domiciliar na formação médica.

Trata-se de estudo exploratório de natureza qualitativa, desenvolvido por meio de trabalho de campo na forma de entrevistas semiestruturadas. Foram escolhidos, por conveniência, profissionais de diferentes categorias e serviços de APS do município de Botucatu-SP, sendo: quatro Unidades de Saúde da Família (USF); duas Unidades Básicas de Saúde (UBS) e dois Centros de Saúde Escola (CSE).

Em cada um destes equipamentos, privilegiou-se a escuta de, pelo menos, dois profissionais de nível Superior (médicos (as), enfermeiros (as) e cirurgiões dentistas) e de, pelo menos, um profissional de nível Médio e/ou Fundamental (técnicos de enfermagem e agentes comunitários de saúde), num total de 24 entrevistas. Todos os sujeitos entrevistados estavam envolvidos no processo de ensino no momento da realização da pesquisa.

A pesquisa foi desenvolvida conforme a Resolução 196/96 do Conselho Nacional de Saúde ${ }^{17}$, após ter recebido aprovação pelo Comitê de Ética em Pesquisa da FMB-Unesp.

O marco teórico-conceitual está pautado na abordagem histórico-cultural com base no método explicativo de Vigotski ${ }^{18,19}$. Este referencial compreende que, quando um homem desenvolve uma atividade, ele não se apropria automaticamente de seus conteúdos. Ao serem internalizados, os significados construídos socialmente transformam-se num instrumento subjetivo da relação do indivíduo consigo mesmo, adquirindo, assim, um sentido pessoal.

A trajetória analítico-interpretativa dos depoimentos obedece a uma organização do material em pré-indicadores, que irão compor um quadro amplo de possibilidades de categorização. A partir de um movimento que busca captar temas e questões centrais relatadas pelos indivíduos, é possível estruturar a base para a criação de 'núcleos de significação do discurso'20,21.

O passo seguinte é a sua análise propriamente dita, que se inicia por um processo intranúcleo e avança para uma articulação internúcleos. Tal processo perpassa pela apreensão das determinações, motivações e necessidades que constituíram tais formas de significar, para, com isso, poder se compreender a produção dos sentidos, suas contradições e relações com o contexto social, cultural, político e econômico 20,21 .

A própria construção e o nome dado a cada núcleo já constituiu um movimento de análise, tendo em vista que reúnem e evidenciam questões relevantes para a compreensão dos aspectos pesquisados $^{20}$. 


\section{Apresentação e discussão dos resultados}

\section{O contexto}

A realização deste trabalho ocorreu em cooperação ao desenvolvimento de uma prática de ensino da FMB/Unesp na APS, em parceria com a Secretaria Municipal de Saúde de Botucatu: a Integração Universidade, Serviços e Comunidade (IUSC). Iniciada como um projeto, a IUSC é hoje caracterizada como um conjunto de disciplinas curriculares, ministradas de forma interprofissional, do primeiro ao terceiro ano, aos cursos de graduação em medicina e enfermagem ${ }^{22}$.

A instituição articula as referidas disciplinas obrigatórias das graduações aos projetos Pró-Pet/ Pet-Redes e Pet-Vigilância, que se fazem presentes na rede de saúde por meio de 14 projetos, com a colaboração e participação de: três coordenadores (professores da IES), 14 tutores (professores da IES), sessenta preceptores (trabalhadores das redes de atenção do município) e 132 estudantes (dos cursos de medicina, enfermagem e nutrição), em suas diferentes atividades e ações ${ }^{23}$.

Cabe salientar que toda experiência acumulada pela IUSC ao longo dos anos foi e continua sendo fundamental para o desenvolvimento dos projetos Pet em geral. Em um percurso marcado por momentos de formação, articulação e operacionalização das atividades de ensino na rede de atenção à saúde, colaboraram significativamente para o estreitamento das relações entre IES e SMS, reconhecendo e potencializando o papel formador do sistema de saúde.

\section{Análise dos Núcleos de Significados e de Sentidos}

\section{"A construção do SUS ideal condicionado à necessária vivência na APS"}

Neste núcleo de significação, são trazidos elementos sobre a pertinência e relevância da formação dos profissionais de saúde associada ao conhecimento e particularidades que são inerentes ao cenário da APS. Como podemos observar no relato de MED 3:

“Eu penso que o aluno passa a ter uma visão mais geral da saúde. Sai daquele modelo medicocêntrico. Aqui, eles passam a conhecer e a trabalhar com outros profissionais e isso faz bastante diferença. Aprende a lidar e a conversar com outro tipo de população que eles não estão acostumados".

Ressalta-se que a experiência dos alunos na APS colabora para que haja um maior diálogo e aprendizado com outras categorias, assim como no conhecimento de uma realidade diferente da que estão familiarizados. Além disso, destaca a importância de destronar o médico como único protagonista da saúde, tendo a oportunidade de reconhecer o outro e desenvolver a capacidade de trabalho em equipe.

Como pode ser observada no relato do ACS 2, a inserção de alunos nos cenários da APS favorece o estreitamento relacional e de formação de vínculo com os pacientes, com possibilidades de diminuir barreiras sociais existentes entre médicos e pacientes:

"Caiu àquela coisa do médico no patamar de "santo", o intocável... A gente já tem a intimidade de conversar com ele, já quebra aquela barreira de achar que o doutor é o intocável e eu não sou nada. Então o paciente aproxima mais".

Ressalta que, ao ter uma compreensão ampliada dos pacientes em seu próprio território, conseguem aproximar sua linguagem e condutas de forma mais condizente com as necessidades e anseios da população. Na medida em que não se sentem inferiorizados e intimidados pela disparidade de poder, os pacientes podem encontrar abertura para explicitar verdadeiramente o que pensam e sentem sem medo de possíveis represálias, e a não mais falar aquilo que o "doutor" quer e espera ouvir. 
Já a ENF 4, explicita o papel dos equipamentos de saúde como campo necessário de formação e aprendizagem, vivência que não teve e poderia ter contribuído muito para os conhecimentos e habilidades que the são exigidas no trabalho cotidiano.

"Acho que todo mundo tinha que tá ciente que vai receber alunos, um dia a gente precisou disso... Da mesma forma, todos os alunos precisam aprender e adquirir experiência pra entrar no mundo do trabalho. Se eu tivesse essa experiência que eles têm hoje, teria melhorado muito a minha situação. Tive que correr atrás de um monte de coisas que eu não tive na faculdade".

Compreende-se que a desconstrução do modelo hospitalocêntrico, mediconcêntrico e biologicista também é vislumbrada por meio do conhecimento e contato dos alunos nos cenários da APS. Do mesmo modo, também enfatizam a possibilidade de se conhecerem e incorporarem saberes oriundos de outros campos e categorias profissionais, além de uma maior valorização da APS, e, em particular, da Saúde da Família enquanto um campo em evidência e cada vez mais valorizado na atuação dos futuros profissionais de saúde.

MED 1 também corrobora essa visão ao afirmar que:

“O papel do médico não é mais aquele que eu mando e você obedece. É o de esclarecer o paciente sobre o que ela está fazendo, quais são as possibilidades de tratamento, você negociar e discutir mesmo. Eles aprendem a lidar com esse lado mais humanitário do médico. Aprendem a desenvolver o exercício da escuta, porque médico geralmente não gosta muito de escutar, gosta mais de falar...".

Destaca-se a vivência e aprendizados proporcionados na APS como condição para o desenvolvimento de uma postura mais humanizada e dialógica com a comunidade. MED 1 referenda a necessidade de construção conjunta do tratamento, o que passa pelo desenvolvimento de habilidades de escuta e de reconhecimento do saber prévio trazido pelos pacientes.

Ao integrar o cenário real do SUS, a universidade tem condições de solidificar um arranjo institucional, num processo real de fortalecimento das práticas, assim como, em projetos e pesquisas que envolvam profissionais como autores de fato, e não apenas em agradecimentos ao final dos estudos.

"O contínuo aprendizado e crescimento profissional proporcionado pela interação com os alunos"

Na configuração deste segundo núcleo, estão reunidas falas que ilustram não apenas a valorização da experiência na formação dos futuros profissionais, mas, também, uma série de benefícios advindos desta interação, que se refletem numa maior instrumentalização técnica e qualificação do cuidado ofertado à população.

MED 4 aponta a valorização do conhecimento novo adquirido no contato com os alunos que estão em processo de formação:

“Eles chegam e trazem novidade pra gente de dentro da universidade. Então nós também aprendemos muitas coisas com eles. - Oh Professora! Fui numa palestra e fulano falou isso... É claro que você não acha isso num livro, nem no trabalho do dia-a-dia".

A entrevistada ressalta que, embora seja reconhecida como professora no cenário da APS, sente que sua prática é enriquecida num processo dialético de ensino-aprendizagem, apropriando-se de conhecimentos oriundos de espaços pertencentes ao universo dos alunos e que vão muito além das possibilidades vislumbradas em seu trabalho cotidiano.

Do mesmo modo, ENF 6 aponta que a relação com os alunos the coloca a necessidade de estudar e se atualizar constantemente, conferindo maior envolvimento e comprometimento com 
o próprio trabalho: "Acho que os alunos me exigem mais, vão te questionar mais, vão trazer novos conhecimentos, novos procedimentos. Eu acho que os profissionais ficam mais envolvidos e estimulados pelo contato".

De maneira semelhante, DENT 2 referenda a possibilidade de desenvolvimento e qualificação profissional para uma abordagem integral dos indivíduos:

“Foi ampliando muito mais a minha visão na questão de saúde geral das pessoas, da integralidade do cuidado. Antes eu ficava muito fechada só na minha área e não conseguia enxergar a relação de outras coisas que estão interferindo... Como tutora do IUSC tive que abrir muito a minha cabeça, aprender sobre várias coisas que eu não tinha conhecimento e vejo que agregou e melhorou a minha prática".

Tendo de problematizar com seus alunos a configuração de novas modalidades de cuidado em saúde, se viu desenvolvendo uma nova prática que incorporou saberes no seu trabalho cotidiano, como numa maior compreensão e atenção as múltiplas determinações do processo saúde-doença.

Este cenário revela que a presença de alunos em contato com os profissionais da APS não é, por si só, garantia de mudanças e transformações no cotidiano de trabalho. A Educação Permanente adquire papel fundamental como eixo transversal e transformador desta realidade, contribuindo na regulação da formação em saúde conforme as necessidades do SUS, o que deve envolver as dimensões política e pedagógica fundamentadas em mecanismos de problematização e instrumentalização para uma prática mais refletida e qualificada.

"O aprendizado na comunidade no presente como estratégia para um futuro retorno social"

Neste núcleo, repousam as concepções dos profissionais de saúde quanto à relevância da formação em serviço para a comunidade na qual os alunos estão inseridos, assim como para toda a sociedade em geral. Tais aspectos podem ser observados no relato de ENF 5, ao afirmar que:

"Quando eu faço as visitas e solicitamos a possibilidade de acompanhamento dos alunos, a gente coloca o propósito do trabalho, e fala que é pra futuramente ter um profissional que conheça o local, a realidade daquela população, e não vai ficar fechado lá no hospital sem saber o que tá acontecendo aqui fora... Elas acham ótimo e se sentem felizes por estar recebendo".

Seu discurso destaca que a população é solidária à importância do aprendizado, sobretudo quando o caráter da proposta é da relevância de seu papel nesta experiência. Ter a oportunidade de favorecer a construção de uma saúde pública mais humanizada e atenta aos anseios e problemáticas enfrentadas pela população no cotidiano da assistência é vista com bons olhos por aqueles que podem e gostariam de colaborar com o processo formativo.

MED 8 aponta que, pela posição que o aluno ocupa, uma série de aspectos envolvidos na abordagem com o paciente são facilitados:

“Eu acho que eles ficam mais confortáveis pra falar com os alunos. Porque eles não têm coragem de falar com os médicos que não têm condições de comprar o remédio... Acho que a comunidade ganha quando o médico compreende mais a realidade e o jeito de ser do paciente, a dificuldade que é ter que tomar um remédio para o resto da vida, que alguns pacientes encaram um diagnóstico com pesar, outros com naturalidade, outros vão fazer um esforço pra comprar e outros já não vão fazer isso".

O médico corrobora a necessidade de aproximação com os pacientes como fator essencial para a responsabilização com sua própria saúde. A falta de aderência ao tratamento não deve ser vista como uma afronta ao médico ou descaso com a própria saúde, mas, sim, compreendida a partir das idiossincrasias de cada paciente em dada situação, onde uma série de mecanismos de defesa e 
questões de ordem econômica pode incidir no modo como o indivíduo recebe o seu diagnóstico e se engaja no tratamento proposto.

Já DENT 2, apresenta a possibilidade de ganhos da população que será atendida por futuros profissionais com uma ampliação do diálogo com médicos que se tornam mais humanos ao lidarem com os pacientes: "Pra sociedade é muito bom. Porque você vai formar um profissional que sabe escutar, sabe se comunicar. Muitas vezes a gente vai se consultar com médicos e nem olha na sua cara. Então eu passo isso para os meus alunos, porque a gente sabe que hoje em dia as doenças são muito psicossociais".

Percebe-se o cuidado em desenvolver uma atitude empática com os pacientes tendo como base a reflexão quanto à experiência de cada um quando tratados de modo negligente e fortuito em momentos de fragilidade e adoecimento.

Para tanto, a diversificação dos cenários e a utilização de metodologias problematizadoras são compreendidas como estratégias para a transformação curricular, pois aproximam os estudantes da vida cotidiana e contribuem para desenvolver olhares críticos e voltados para os problemas reais da população.

Mesmo que os benefícios ainda não sejam totalmente evidentes, no momento em que estão sendo desenvolvidos os trabalhos, estão colocadas as potencialidades desta experiência na construção de um profissional de saúde menos autoritário, mais seguro e mais consciente de seu papel social.

\section{“O cenário de possibilidades de aprendizagem limitado pelo espaço físico das unidades de saúde"}

A centralidade deste núcleo de significação versa sobre os apontamentos quanto aos reflexos e interferências da presença de alunos no processo de trabalho e na dinâmica de funcionamento da instituição como um todo.

\footnotetext{
"A gente tem que se organizar pra isso, porque embora talvez pareça que posto é amplo tem momento que a gente não tem aonde todo mundo atender... Mas tem uma contribuição, porque às vezes traz outro olhar, pode contribuir de uma outra maneira que na correria do diaa-dia a gente não tem tempo pra tocar uma atividade de promoção e prevenção..."
}

Conforme podemos perceber, ENF 1 reconhece as limitações estruturais do seu local de trabalho ao não apresentar condições satisfatórias aos alunos. Contudo, observa-se que a mesma não lhes apresenta um ideário de trabalho condizente com as particularidades da APS, delegando aos alunos propostas tidas como secundárias e negligenciadas pela equipe de saúde.

Outros aspectos são apresentados por MED 2:
“Você tem que ter toda equipe preparada e capacitada pra receber alunos... A partir do momento que o IUSC ficou com disciplina obrigatória, acabou tendo que aluno atender em dupla e isso é ruim... Como a gente tinha grupos menores eles tinham mais disponibilidade de espaço... Se você tem um menor número de alunos você consegue dar uma atenção maior...".

Sua concepção aponta que a transformação da IUSC em disciplina trouxe consigo outras problemáticas na interação entre profissionais e alunos que se repercutem na organização do serviço. Ressalta que essas tensões podem ser minimizadas pela preparação prévia e envolvimento de todos os profissionais da equipe. Mais do que isso, sugere que esta tarefa não é reconhecida dentro do rol de atribuições, devendo ser engendrada na forma de capacitação e educação continuada de seus trabalhadores.

Apesar de todas essas dificuldades, as equipes de saúde têm procurado se adequar perante este contexto de trabalho por meio da improvisação de salas, rodízio em dias alternados, assim como na realização de supervisões em grupo, que, embora ajudem a minimizar, não resolvem, de fato, os problemas. 
O relato de ENF 3 corrobora essa visão, ressaltando as dificuldades vivenciadas pela unidade diante de condições inadequadas de infraestrutura, que também se refletem em sua menor capacidade de incorporar alunos em suas atividades: "Se tivesse mais estrutura física, tivesse mais salas, eu acho que daria pra mais alunos estarem atendendo... Tem dia que um dos alunos atende lá na sala de eletro, faz um consultório lá...".

A problemática revela que estas estruturas não têm sido construídas de maneira a atender as prerrogativas de cuidado na APS. Isso se verifica na incongruência destes dispositivos que, por não se verem em condições favoráveis, acabam por abdicar de uma série de ações que deveriam ser parte integrante do seu processo de trabalho, a exemplo das atividades em grupo e de educação em saúde.

Tais constatações clarificam contradições presentes nas políticas públicas que enfatizam a APS e, em especial, a ESF como estratégias fundamentais para a ampliação do acesso e no modo em que são ofertados os cuidados em saúde no Brasil, mas que, ainda, encontram condições nem sempre adequadas para se efetivarem.

“Interferências e incongruências da gestão municipal de saúde e da mudança da mesma na execução de atividades pedagógicas na APS"

Neste núcleo, são apresentados apontamentos e insatisfações dos profissionais quanto às mudanças e direcionamentos dados pela gestão municipal de saúde em relação às atividades de cunho pedagógico na APS.

Ao se referir às implicações da gestão nas atividades, MED 6 coloca que:

"A mudança de gestão atrapalha sim. Agora nós estamos sendo cobrados por produtividade. É acordado que nós temos que atender um certo número de pacientes por período, desenvolver tais e tais ações...Na medida que a gente fica amarrado só na produção, acaba tendo que abrir mão e não pode se dedicar a outras coisas".

MED 6 ressalta a preocupação com a mudança na gestão municipal e com as prioridades no trabalho que também se modificam. Conforme a cobrança por produtividade aumenta, outras ações e frentes de trabalho sofrem prejuízos, a exemplo das atividades de ensino.

Questões que também são partes indecomponíveis na organização e operacionalização dos preceitos do SUS são negligenciadas e secundarizadas, o que demonstra o desconhecimento na legitimação do papel formador do sistema, assim como na ausência de interlocução e construção de um projeto de trabalho a médio e longo prazo com os profissionais de saúde.

MED 1 corrobora tal perspectiva e argumenta que as mudanças de uma administração para outra afetam o processo de trabalho, com consequências para todos os envolvidos:

“Tem aqueles programas do MS que a gente procura cumprir. Não cumpre ao pé da letra, mas a gente tem que passar isso pros alunos... Aí muda a gestão com uma ideia que foge completamente a tudo que a gente fazia e acredita que deva ser o Programa. Isso atrapalha? Atrapalha. Porque você tá falando uma coisa pro aluno e tá fazendo outra...".

Diante da desconstrução dos projetos e ações em curso quando novos personagens assumem a gestão, os relatos trazem à tona um perverso "jogo" de vaidades e de interesses políticos que, mesmo que não sejam totalmente explícitos, interferem no modus operandi das diversas ações executadas pelas unidades de saúde.

Tais interferências, além de não demonstrarem preocupação quanto aos reais beneficiários da assistência, colaboram para o desgaste e sofrimento emocional dos profissionais, que, em muitos momentos, sentem-se hipócritas em defender uma visão de mundo e de proposta de trabalho que se mostram incoerentes com o que de fato desenvolvem. 


\section{"Os projetos indutores de mudança do MS \\ e suas implicações na sustentabilidade das atividades de ensino na APS"}

Estão apresentadas, neste núcleo, questões referentes à pactuação de ações entre responsáveis pela coordenação e condução das atividades acadêmicas no âmbito da universidade junto a gestores e profissionais que atuam na APS. Quanto aos aspectos que dizem respeito à coordenação e operacionalização da disciplina, profissionais como a DENT 1 manifesta que:

\footnotetext{
"A gente acaba escutando muito boato que vai acabar o PET, pelo menos aqui no município... Eles estariam meio revoltados, porque é muita pressão pra colocar tal pessoa como coordenador, tal como tutor, quem eles quisessem da secretaria... Eu não sei nem se isso é verdade, mas daí eu acho que interfere nesse ponto...".
}

Sua percepção revela que comentários que circulam nos bastidores das Unidades de Saúde na forma de boatos também interferem no andamento das ações. Tal constatação alerta que propostas como a da IUSC e do PET-Saúde geram, em algumas situações, desentendimento e disputas entre funcionários e assessores da SMS, profissionais da rede e os responsáveis pela coordenação dos projetos.

Embora a "bolsa" disponibilizada aos profissionais envolvidos diretamente com os projetos tenha um caráter de incentivo pelo MS, é notório que suas repercussões podem chegar muito além. Tendo em vista o histórico de participação e envolvimento das equipes com as propostas de ensino pactuadas entre as IES e SMS, o auxílio financeiro passa a adquirir status de complementação salarial para os profissionais que se veem mal remunerados com o piso básico oferecido na contratação, particularmente os profissionais não médicos.

De modo semelhante, DENT 3 coloca que:

"Acho que as ACS se sentem muito sobrecarregadas... Falta uma motivação maior pra elas também. No ano passado tinha uma bolsa pra as ACS e parou de vir... Mas não só o dinheiro, falta também capacitação, cursos... Na parte médica e de enfermagem tem bastante, mas as outras áreas ficam um pouco de lado..."

Mesmo os profissionais que atuam diretamente como tutores e recebem gratificações financeiras, percebem o descontentamento e se solidarizam com os demais colegas de equipe que não têm ou deixaram de ter esse "privilégio". Além disso, apresentam a necessidade de valorização e empoderamento das ações pedagógicas dos outros profissionais da equipe para além da questão financeira.

Este cenário demonstra que as políticas indutoras de mudanças na educação e na prática da saúde pública brasileira ainda encontram aspectos limitantes, e que necessitam maior reflexão, tendo em vista uma transformação maior, haja vista que um sistema de saúde universal, integral e equânime não se efetiva sem que todos sejam vistos como parte fundamental de um mesmo projeto.

\section{"A desvalorização da APS como campo de atuação profissional do médico"}

Aqui, estão reunidos relatos que trouxeram questionamentos quanto ao processo de transformação curricular da universidade local e de como as mudanças almejadas ainda não eram consensuais dentro da própria academia.

É importante destacar que, a partir de 2013, iniciou-se um novo movimento de reforma na grade curricular do curso de graduação em medicina da IES. Sua construção está em fase de finalização e tem sido permeada por inúmeras oficinas, debates e propostas de integração disciplinar e departamental, sendo valorizados e incorporados muitos dos preceitos teórico-metodológicos que dão sustentação à IUSC. 
Mesmo trabalhando como um profissional na ponta da assistência, a ACS 4 revela que sente os reflexos das tensões e divergências na formação apontadas acima, que se fazem presentes na resistência e postura dos alunos:

"Eu sei por vários alunos que já passaram por aqui, que eles tinham uma comunidade na internet: "eu odeio Saúde Pública" e eu perguntava por quê? Aí alguns disseram que era porque na teoria quando eles têm aula, falam que é horrível, era desorganizado. Quando eles iam pra unidade, por ter essas aulas que são meio desgastantes, já vêm com aquela má vontade. Mas depois quando chega aqui eles têm uma outra visão, mas depende muito do aluno".

MED 1 revela sua experiência enquanto profissional que renunciou à própria especialidade e pactua com a necessidade de revisão dos currículos para uma formação que faça jus aos princípios do SUS. Seu discurso alerta que ainda é muito forte a visão negativa do trabalhador da APS, visto como menos qualificado e mal remunerado:

“Está sendo discutido o novo currículo da medicina, estão tendo várias oficinas pra adequação do currículo. Os médicos da minha época têm uma ideia diferente e eu também tinha até vir trabalhar na Saúde da Família. Inclusive fui super criticada por largar tudo, o pessoal achava que eu tava regredindo, renunciando a minha especialidade... Os colegas que têm o mesmo tempo de formação que eu acham inútil... Falavam coisas absurdas. Tipo, o médico é soberano, ele manda você abrir a boca tomar o remédio e pronto. E hoje em dia o povo tem muito mais acesso à informação. Eles discutem com você sobre a sua conduta...".

Sua constatação nos apresenta que esse ideário também repercute na postura do médico, colocando-o numa condição acima dos demais, desconsiderando o saber prévio da população e a necessidade de uma postura dialógica com os pacientes. Mais do que isso, explicita o desconhecimento da Saúde Pública enquanto grande campo de atuação dos futuros profissionais de saúde, assim como da necessidade de revisão dos currículos que ainda não se adequaram a estas novas configurações.

\section{Considerações finais}

Embora a proposição, os fomentos e incentivos para reformas nos currículos do ensino na saúde estejam transformando antigas concepções e práticas alicerçadas no modelo biomédico em todo território nacional, são grandes os desafios a serem enfrentados e superados, demonstrando tensões em um movimento de mudança ainda contra-hegemônico.

A necessidade de uma formação inserida na concretude prática dos serviços na rede de atenção, no cuidado responsável do paciente, família e comunidade, comprometida com demandas sociais que possa questionar os caminhos do desenvolvimento da medicina tecnológica, da fragmentação do cuidado e a mercantilização do trabalho na saúde - está em construção.

Diante desse quadro, revela-se a importância de um estreitamento comunicacional entre os coordenadores dos projetos, gestores e profissionais, assim como uma maior preocupação com a inserção de docentes e alunos para o trabalho na APS, articulando ações que aliem a formação no e pelo trabalho, às demandas e necessidades da população e da equipe de saúde.

Como podemos constatar, as IES articuladas com equipamentos e serviços de saúde cumprem papel primordial para que o SUS funcione em consonância com seus princípios. Além das normas e legislações que norteiam a organização e funcionamento da saúde, o preparo técnico e o compromisso ético do estudante, desde os primeiros anos da graduação, poderão contribuir para que se materializem, de fato, ações condizentes com as demandas e necessidades da população.

Frente os inúmeros desafios que concorrem para a consolidação do SUS necessário, torna-se crucial efetivar espaços de Educação Permanente, a partir de caminhos de reflexão sobre a prática 
cotidiana, norteadas por aportes teóricos que fundamentem o trabalho em concepções dialógicas e compromissadas com a integralidade do cuidado.

Apesar das limitações do estudo, salienta-se que o objeto de investigação desenvolvido a partir da metodologia empregada, permitiu identificar a necessidade de uma série de ajustes e negociações entre órgãos formadores, unidades de saúde e gestores encarregados desta articulação, para que alunos, professores, trabalhadores e população possam ser beneficiados com esta intervenção.

\section{Colaboradores}

Os autores trabalharam juntos em todas as etapas de produção do manuscrito.

\section{Referências}

1. Ministério da Saúde (BR), Secretaria de Políticas de Saúde, Coordenação Geral da Política de Recursos Humanos. Programa de incentivos às mudanças curriculares para as escolas médicas (PROMED). Brasília, DF: Ministério da Saúde; 2002.

2. Ministério da Saúde (BR); Ministério da Educação (BR). Programa Nacional de Reorientação da Formação Profissional em Saúde - PRÓ-SAÚDE. Brasília, DF: Ministério da Saúde; 2005.

3. Ministério da Saúde (BR). Portaria $n^{\circ}$ 754, de 18 de abril de 2012. Altera a Portaria $\mathrm{n}^{\circ} 1.111 / \mathrm{GM} / \mathrm{MS}$, de 5 de julho de 2005, que fixa normas para a implementação e a execução do Programa de Bolsas para a Educação pelo Trabalho. Diário Oficial União. 20 abr. 2012.

4. Ministério da Saúde (BR), Secretaria de Gestão do Trabalho e da Educação na Saúde. Edital no 14, de 8 de março de 2013. Seleção para o Programa de Educação pelo Trabalho para a Saúde/Redes de Atenção à Saúde - 2013/2015. Diário Oficial União. 11 mar. 2013;Seção3:116-8.

5. Ministério da Saúde (BR). Resolução n 3, de 20 de junho de 2014. Estabelece Diretrizes Curriculares Nacionais do curso de graduação em medicina. Brasília (DF): Conselho Nacional de Educação Superior; 2014. 
6. Passarela TM. Programa de Educação pelo Trabalho para a Saúde - PET-Saúde/Saúde da Família: um estudo sobre a percepção dos participantes acerca da integração ensinoserviço-comunidade [dissertação]. Rio de Janeiro: Escola Nacional de Saúde Pública Sergio Arouca; 2013.

7. Feuerwerker LCM. Gestão dos processos de mudança na graduação em medicina. In: Marins, JJN Rego S, Lampert JB, Araújo JGC, organizadores. Educação médica em transformação: instrumentos para construção de novas realidades. São Paulo: Hucitec; 2004. p. 17-39.

8. Lampert JB, Costa, NMSC, Perim, GL, Ively GA, Aguilar-da-Silva RH, Stela, RCR. Tendências de mudanças em um grupo de escolas médicas brasileiras. Rev Bras Educ Med. 2009;33(1):19-34. http://dx.doi.org/10.1590/S0100-55022009000500003

9. Sisson MC. Identidades profissionais na implantação de novas práticas assistenciais. Rev Bras Educ Med. 2009;33(supl 1):116-22. http://dx.doi.org/10.1590/S010055022009000500013

10. Leite MTS, Rodrigues CAQ, Mendes, DC, Veloso NS, Andrade JMO, Rios LR. O programa de educação pelo trabalho para a saúde na formação profissional. Rev Bras Educ Med. 2012; 36(1 supl 1):111-8. http://dx.doi.org/10.1590/S0100-55022012000200015

11. Campos MAF, Forster AC. Percepção e avaliação dos alunos do curso de medicina de uma escola médica pública sobre a importância do estágio em saúde da família na sua formação. Rev Bras Educ Med. 2008; 32(1):83-9. http://dx.doi.org/10.1590/S010055022008000100011

12. Feuerwerker LCM, Capozzolo AA. Mudanças na formação dos profissionais de saúde: alguns referenciais de partida do eixo trabalho em saúde. In: Capozzolo AA, Casseto SJ, Henz $A O$, organizadores. Clínica comum: itinerários de uma formação em saúde. São Paulo: Hucitec; 2013. p. 35-57.

13. Junqueira $V$, Frutuoso $M F$, Silva $C R C$. Os (des)compassos entre a universidade e os serviços de saúde. In: Capozzolo AA, Casseto SJ, Henz AO, organizadores. Clínica comum: itinerários de uma formação em saúde. São Paulo: Hucitec; 2013. p. 229-47.

14. Albuquerque VS, Gomes AP, Rezende CHA, Sampaio MX, Dias OV, Lugarinho RM. A integração ensino-serviços no contexto dos processos de mudança na formação superior dos profissionais de saúde. Rev Bras Educ Med. 2008; 32(3):356-62. http://dx.doi. org/10.1590/S0100-55022008000300010

15. Pizzinato A, Gustavo AS, Santos BRL, Ojeda BS, Ferreira E, Thiesen FV et al.. A integração ensino-serviço como estratégia na formação profissional para o SUS. Rev Bras Educ Med. 2012;36(1 supl 2):170-7. http://dx.doi.org/10.1590/S010055022012000300025

16. Trajman A, Assunção A, Venturini M, Tobias D, Toschi W, Brant V. A preceptoria na rede básica da Secretaria Municipal de Saúde do Rio de Janeiro: opinião dos profissionais de saúde. Rev Bras Educ Med. 2009; 33(1):24-32. http://dx.doi.org/10.1590/S010055022009000100004

17. Ministério da Saúde (BR). Conselho de Saúde. Resolução nº 196, de 10 de outubro de 1996. [Estabelece diretrizes e normas regulamentadoras de pesquisas envolvendo seres humanos]. Diário Oficial União; 16 out 1996.

18. Vigotski LS. A construção do pensamento e da linguagem. São Paulo: Martins Fontes; 2001.

19. Vigotski LS. Historia del desarrollo de las funciones psíquicas superiores: visor dist. Madri: Visor; 1995. (Obras escogidas, v.3.)

20. Aguiar WMJ, Ozella, S. Apreensão dos sentidos: aprimorando a proposta dos núcleos de significação. Rev Bras Estud Pedagog. 2013; 94(236):299-322. http://dx.doi.

org/10.1590/S2176-66812013000100015 
21. Aguiar WMJ, Ozella S. Núcleos de significação como instrumento para apreensão da constituição dos sentidos. Psicol Ciênc Prof. 2006;26(2):222-45. http://dx.doi. org/10.1590/S1414-98932006000200006

22. Cyrino EG. Ampliando parcerias para o ensino significativo na atenção básica à saúde: o Programa Interação Universidade, Serviço e Comunidade - IUSC da Faculdade de Medicina de Botucatu - Unesp. In: Anais do Encontro de experiências bem-sucedidas de integração ensino-serviço; 1995; Joinvile, Brasil. p. 2-16.

23. Cyrino EG. Ensino e pesquisa na estratégia de saúde da família: o PET-Saúde da FMB/ UNESP. Rev Bras Educ Med. 2012;36(1 supl 1):92-101. http://dx.doi.org/10.1590/S010055022012000200013

Pinto TR, Cyrino EG. Con la palabra, el trabajador de la atención primaria de salud: potencialidades y desafíos en las prácticas educativas. Interface (Botucatu). 2015; 19 Supl 1:765-77

Este estudio investiga el potencial y los obstáculos en la consolidación e implementación de actividades de enseñanza y aprendizaje en la interacción entre los estudiantes y los trabajadores de atención primaria de salud (APS). Se realizó una investigación cualitativa mediante entrevistas semi-estructuradas con profesionales de diferentes categorías y servicios de APS de un municipio de tamaño medio de São Paulo. Los datos se analizaron según el enfoque histórico- cultural, de acuerdo con el método explicativo de Vygotsky. Se encontró que los escenarios de APS se han establecido como un campo de aprendizaje clave para una educación que cumpla con los principios del SUS. Sin embargo, es necesaria una serie de ajustes y acuerdos entre los órganos formadores, unidades de salud y gestores a cargo de esta articulación, para que los estudiantes, los profesores, los trabajadores y la población puedan ser beneficiados con esta intervención.

Palabras clave: Educación em salud. Atención primaria de salud. Grupo de atención al paciente. 
